\title{
UJI EFEK PENYEMBUHAN LUKA SEDIAAN GEL EKSTRAK ETANOL DAUN AFRIKA (VERNONIA AMYGDALINA.DEL) PADA MENCIT JANTAN
}

\author{
Ernawaty, Tri Bintarti, Maya Handayani \\ Jurusan Farmasi Poltekkes Kemenkes Medan \\ ernawatyn@yahoo.com
}

\begin{abstract}
African leaf (Vernonia amygdalina) is one of the potent plants as antidiabetic, antibacterial, antifungal, analgesic and antioxidant. The aims of this study was to determine the wound healing effect of ethanolic extract of african leaves gel and obtain an effective formula. It was an experimental research. Injuries were made by cutting the back of mice's skin with diameter $\pm 1 \mathrm{~cm}$. Fourty eight mice were divided into 8 groups, one group as control, EEDA 1\%, EEDA 3\%, EEDA 5\%, EEDA 7\%, EEDA 9\%, Bioplacenton as positif control and base gel group. The observation was done by measured the diameter of wound visually. The mice declared cure and marked growth of new skin and hair around the wound. At the end of the test performed histophatological test. This study concluded the ethanol extract of Africa leaves have wound healing effect in mice and EEDA 9\% have wound healing effect at $15^{\text {th }}$ daya.
\end{abstract}

Keywords: ethanol extract of africa leaves, wound

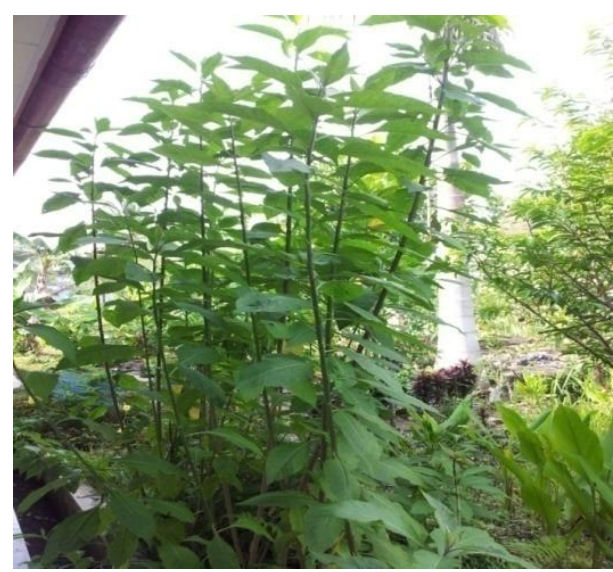

Daun Afrika (Vernonia amygdalina)

\begin{tabular}{|c|c|}
\hline Kingdom & : Plantae \\
\hline Divisi & : Spermatophyta \\
\hline \multicolumn{2}{|c|}{ Subdivisi: Angiospermae } \\
\hline Klas & : Dicotyledoneae \\
\hline Ordo & : Asteraceae \\
\hline Genus & : Vernonia \\
\hline Spesies & : Vernonia amygdalina Del. \\
\hline
\end{tabular}

\section{TUJUAN PENELITIAN}

Tujuan penelitian ini adalah untuk menentukan efek penyembuhan luka gel ekstrak etanol daun afrika dan menetukan formula efektif gel.

\section{METODE PENELITIAN}

Daun afrika dikumpulkan dari lingkungan Fakultas Farmasi, Universitas Sumatera Utara, Medan, dan diidentifikasi di Herbarium Medanense (MEDA,) Universitas Sumatera Utara.

Formula Gel Ekstrak Etanol Daun Afrika

\begin{tabular}{|c|c|c|c|c|c|}
\hline & \multicolumn{5}{|c|}{ Formula } \\
\hline & $\begin{array}{l}\text { EEDA } \\
1 \%\end{array}$ & EEDA 3 & $\begin{array}{l}\text { EEDA } \\
5 \%\end{array}$ & $\begin{array}{l}\text { EEDA } \\
7 \%\end{array}$ & $\begin{array}{l}\text { EEDA } \\
9 \%\end{array}$ \\
\hline EEDA & $1 \mathrm{~g}$ & $3 \mathrm{~g}$ & $5 \mathrm{~g}$ & $7 \mathrm{~g}$ & $9 \mathrm{~g}$ \\
\hline $\mathrm{Na} \mathrm{CMC}$ & $200 \mathrm{mg}$ & $200 \mathrm{mg}$ & $200 \mathrm{mg}$ & $200 \mathrm{mg}$ & $200 \mathrm{mg}$ \\
\hline $\begin{array}{l}\text { Metyl } \\
\text { Paraben }\end{array}$ & $180 \mathrm{mg}$ & $180 \mathrm{mg}$ & $180 \mathrm{mg}$ & $180 \mathrm{mg}$ & $180 \mathrm{mg}$ \\
\hline Air Suling & $2 \mathrm{~mL}$ & $2 \mathrm{~mL}$ & $2 \mathrm{~mL}$ & $2 \mathrm{~mL}$ & $2 \mathrm{~mL}$ \\
\hline Glyserin ad & 100 & 100 & 100 & 100 & 100 \\
\hline
\end{tabular}

EEDA = Ekstrak Etanol Daun Afrika

\section{Evaluasi Gel.}

Uji organoleptik, homogenitas dan $\mathrm{pH}$ selama 35 hari (Hari ke 0, 7, 14, 28 dan 35).

\section{Uji Penyembuhan Luka}

Luka dibuat dengan menyayat punggung belakang mencit dengan diameter luka $\pm 1 \mathrm{~cm}$. Empat puluh delapan mencit dibagi menjadi 8 kelompok, satu sebagai kelompok kontrol, EEDA 1\%, EEDA 3\%, EEDA $5 \%$, EEDA 7\%, EEDA 9\%, Bioplacenton sebagai kontrol positif dan kelompok dengan dasar gel. Pengamatan dilakukan dengan mengukur diameter luka secara visual, tingkat kesembuhan dan pertumbuhan rambut disekitar luka. Pada akhir pengujian, dilakukan uji histopatologi.. 


\section{HASIL}

Tabel 1. Uji Organoleptis Gel Ektrak Etanol Daun Afrika

\begin{tabular}{ccccccc}
\hline \multirow{2}{*}{ Pengamatan } & Formula & 0 & 7 & 14 & 28 & 35 \\
\cline { 3 - 7 } Bentuk & F1 & - & - & - & - & - \\
& F2 & - & - & - & - & - \\
& F3 & - & - & - & - & - \\
& F4 & - & - & - & - & - \\
& F5 & - & - & - & - & - \\
& F6 & - & - & - & - & - \\
\hline \multirow{2}{*}{ Warna } & F1 & - & - & - & - & - \\
& F2 & - & - & - & - & - \\
& F3 & - & - & - & - & - \\
& F4 & - & - & - & - & - \\
& F5 & - & - & - & - & - \\
& F6 & - & - & - & - & - \\
\hline \multirow{2}{*}{ Bau } & F1 & - & - & - & - & - \\
& F2 & - & - & - & - & - \\
& F3 & - & - & - & - & - \\
& F4 & - & - & - & - & - \\
& F5 & - & - & - & - & - \\
& F6 & - & - & - & - & - \\
\hline
\end{tabular}

Tabel 2. Uji Homogenitas Gel Ekstrak Etanol Daun Afrika

\begin{tabular}{ccccccc}
\hline \multirow{2}{*}{ Pengamatan } & \multirow{2}{*}{ Formula } & 0 & 7 & 14 & 28 & 35 \\
\cline { 3 - 7 } Homogenitas & F1 & - & - & - & - & - \\
& F2 & - & - & - & - & - \\
& F3 & - & - & - & - & - \\
& F4 & - & - & - & - & - \\
& F5 & - & - & - & - & - \\
& F6 & - & - & - & - & - \\
\hline
\end{tabular}

Tabel 3. Uji pH Gel Ekstrak Etanol Daun Afrika

\begin{tabular}{ccccccc}
\hline \multirow{2}{*}{ Formula } & pH & \multicolumn{5}{c}{ Hari ke- } \\
\cline { 3 - 6 } & 1 & 0 & 7 & 14 & 28 & 35 \\
\hline F1 & 2 & 6,2 & 6,2 & 6,2 & 6,2 & 6,1 \\
& 3 & 6,2 & 6,1 & 6,2 & 6,2 \\
& 1 & 6,3 & 6,3 & 6,1 & 6,1 & 6,1 \\
\hline F2 & 2 & 6,2 & 6,2 & 6,2 & 6,1 & 6,1 \\
& 3 & 6,2 & 6,2 & 6,1 & 6,1 & 6,0 \\
& 35 & 6,3 & 6,2 & 6,1 & 6,0 & 6,1 \\
\hline & 1 & 6,2 & 6,1 & 6,2 & 6,0 & 6,0 \\
& 2 & 6,3 & 6,1 & 6,1 & 6,1 & 6,0 \\
& 3 & 6,3 & 6,1 & 6,1 & 6,0 & 6,1 \\
\hline & 1 & 6,2 & 6,2 & 6,1 & 6,1 & 6,0 \\
& 2 & 6,3 & 6,2 & 6,1 & 6,1 & 6,1 \\
& 35 & 6,2 & 6,2 & 6,1 & 6,2 & 6,1 \\
\hline F6 & 3 & 6,3 & 6,3 & 6,2 & 6,1 & 6,1 \\
& 1 & 6,3 & 6,3 & 6,1 & 6,1 & 6,2 \\
& 2 & 6,3 & 6,3 & 6,2 & 6,1 & 6,1 \\
\hline & 3 & 6,2 & 6,2 & 6,2 & 6,1 & 6,0 \\
& 1 & 6,3 & 6,3 & 6,2 & 6,1 & 6,1 \\
& 2 & 6,3 & 6,2 & 6,2 & 6,1 & 6,1 \\
\hline
\end{tabular}


Tabel 4. Data Diameter Penyembuhan Luka

\begin{tabular}{|c|c|c|c|c|c|c|c|}
\hline \multirow[t]{2}{*}{ No } & \multirow[t]{2}{*}{$\begin{array}{r}\text { Group } \\
(\mathrm{N}=6)\end{array}$} & \multirow{2}{*}{$\begin{array}{c}\text { Diameter rata-rata } \\
\text { penyembuhan luka }(\mathrm{mm}) \\
\pm \mathrm{SD}\end{array}$} & \multicolumn{5}{|c|}{$\begin{array}{l}\text { Diameter rata-rata penyembuhan luka }(\mathrm{mm}) \pm \text { SD pada hari } \\
\text { ke- }\end{array}$} \\
\hline & & & 1 & 3 & 5 & 7 & 14 \\
\hline \multirow[t]{3}{*}{1} & Blanko & 8,67 & 8,15 & 8,14 & 7,45 & 6,71 & 2,32 \\
\hline & & \pm & \pm & \pm & \pm & \pm & \pm \\
\hline & & 1,24 & 1,18 & 0,34 & 0,91 & 1,32 & 0,80 \\
\hline \multirow[t]{3}{*}{2} & Dasar Gel & 8,89 & 8,66 & 8,52 & 7,32 & 6,58 & 2,04 \\
\hline & & \pm & \pm & \pm & \pm & \pm & \pm \\
\hline & & 1,26 & 1,48 & 0,86 & 1,13 & 0,51 & 0,42 \\
\hline \multirow[t]{3}{*}{3} & EEDA Gel & 8,88 & 8,53 & 7,63 & 7,13 & 6,43 & 1,69 \\
\hline & $1 \%$ & \pm & \pm & \pm & \pm & \pm & \pm \\
\hline & & 1,13 & 1,16 & 0,73 & 0,95 & 0,40 & 0,54 \\
\hline \multirow[t]{3}{*}{4} & EEDA Gel & 9,37 & 9,06 & 7,14 & 6,97 & 6,28 & 1,67 \\
\hline & $3 \%$ & \pm & \pm & \pm & \pm & \pm & \pm \\
\hline & & 0,84 & 0,94 & 0,79 & 0,54 & 0,96 & 0,42 \\
\hline \multirow[t]{3}{*}{5} & EEDA Gel & 8,54 & 8,05 & 6,98 & 6,35 & 5,85 & 1,36 \\
\hline & $5 \%$ & \pm & \pm & \pm & \pm & \pm & \pm \\
\hline & & 1,17 & 1,21 & 0,41 & 0,40 & 1,22 & 0,78 \\
\hline \multirow[t]{3}{*}{6} & EEDA Gel & 8,39 & 8,02 & 6,13 & 5,86 & 5,21 & 1,21 \\
\hline & $7 \%$ & \pm & \pm & \pm & \pm & \pm & \pm \\
\hline & & 1,12 & 1,19 & 0,48 & 1,37 & 1,04 & 0,38 \\
\hline \multirow[t]{3}{*}{7} & EEDA Gel & 8,81 & 8,46 & 5,73 & 4,75 & 4,21 & 0,39 \\
\hline & $9 \%$ & \pm & \pm & \pm & \pm & \pm & \pm \\
\hline & & 0,80 & 0,67 & 0,57 & 0,56 & 0,99 & 0,45 \\
\hline & Bioplacenton $^{\circledR}$ & 9,10 & 8,44 & 5,67 & 4,95 & 4,11 & 0,60 \\
\hline & & \pm & \pm & \pm & \pm & \pm & \pm \\
\hline & & 0,79 & 0,75 & 0,55 & 0,55 & 0,61 & 0,49 \\
\hline
\end{tabular}
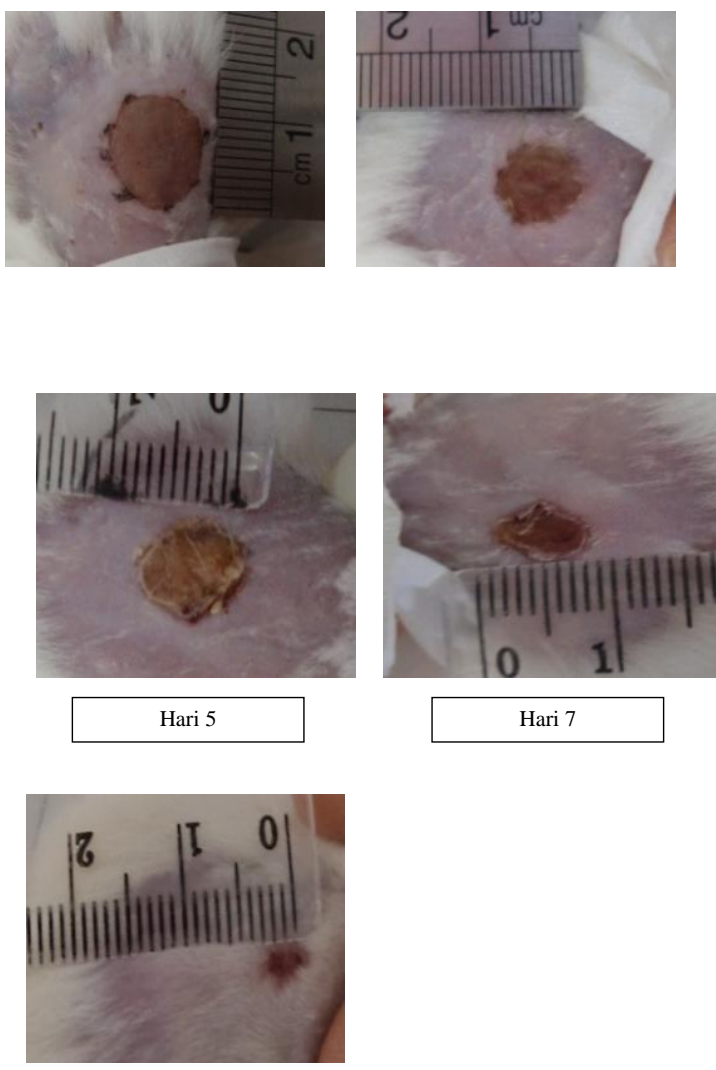

Hari 14

Gambar 1. Diameter Penyembuhan Luka Tanpa Gel
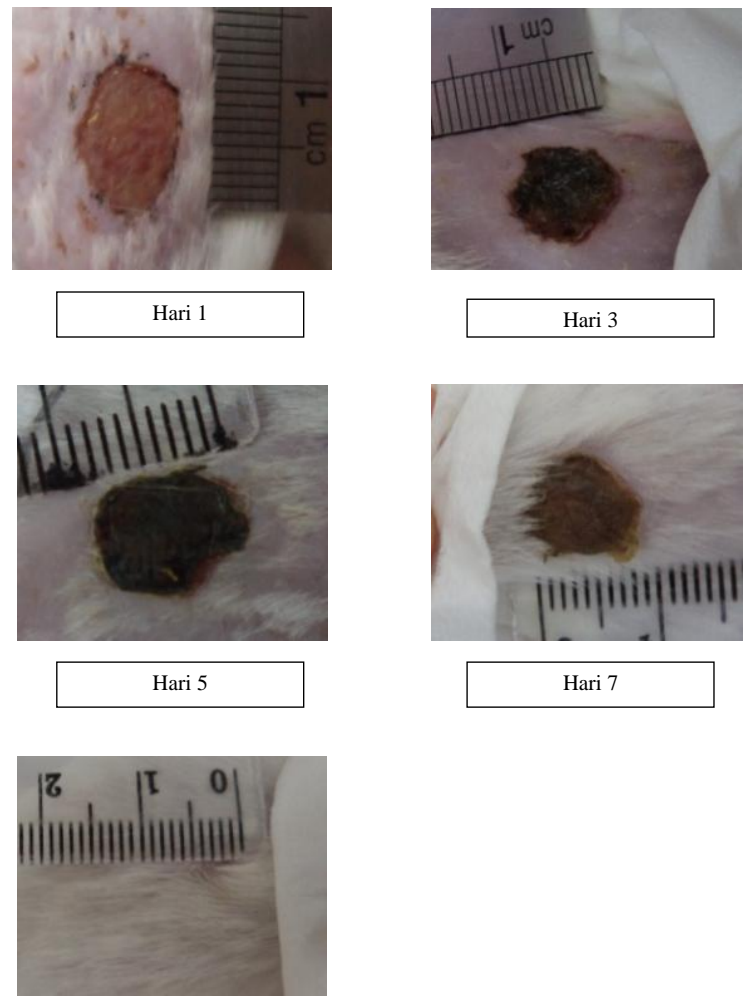

Hari 14

Gambar 2. Diameter Penyembuhan Luka dengan EEDA $9 \%$ 

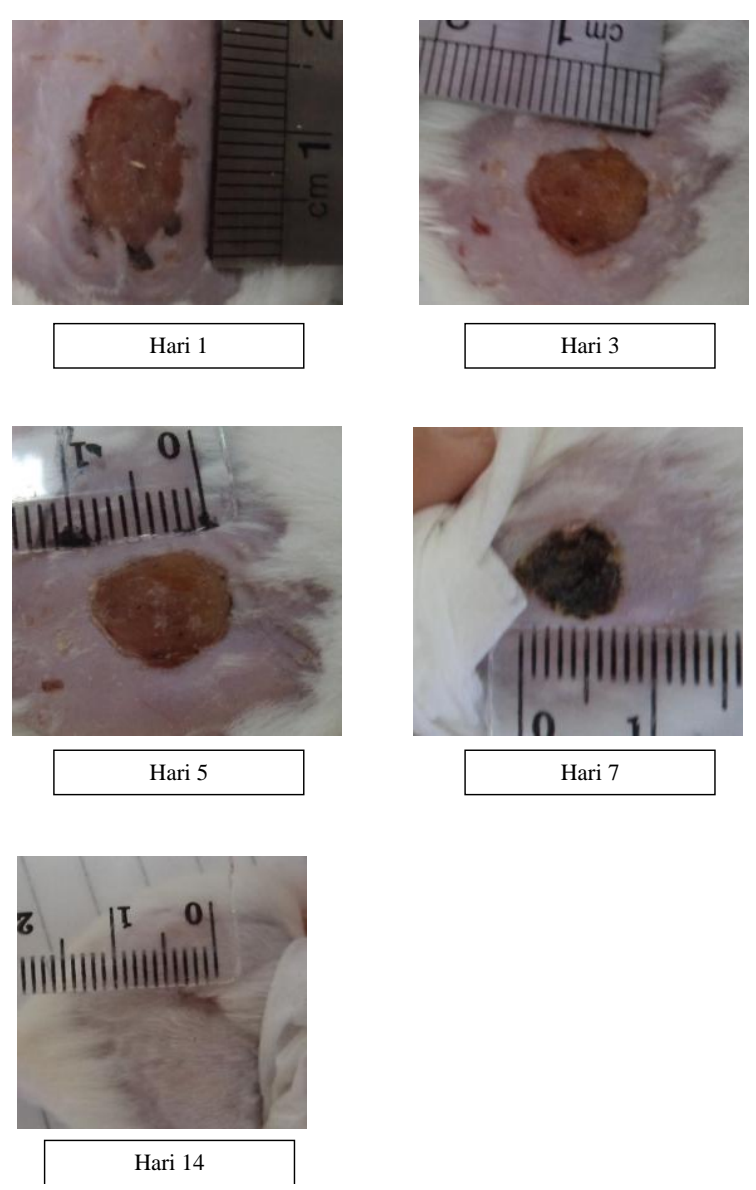

Gambar 3. Diameter PenyembuhanLuka dengan Bioplacenton

\section{SIMPULAN}

Penelelitian menunjukan bahwa ekstrak etanol daun afrika mempunyai efek menyembuhkan luka dengan formula efektif pada EEDA 9\%.

\section{DAFTAR PUSTAKA}

Barku , V. Y. A., A. Boye and S. Ayaba. (2013). Phytochemical Screening and Assessment of Wound Healing Activity of The Leaves of
Anogeissus Leiocarpus. European Journal of Experimental Biology. 3 (4), page. 25.

Ejoh, R.A., Nkonga, D.V., Inocent, G., dan Moses, M.C. (2007). Nutritional Components of Some NonConventional Leafy Vegetables Consumed in Cameroon. Pak. J. Nutr. 6(1): 712-717.

Erasto, P., Grierson, D.S., dan Afolayan, A.J. (2008). Bioactive Sesquiterpene Lactones from The Leaves of Vernonia amygdalina. Int. J. Environ. Res. Public Health. 5(5): 342-348.

Ijeh, I.L., dan Ejike, C.E.C.C. (2010). Current Perspectives on The Medicinal Potentials of Vernonia amygdalina Del. Journal of Medicinal Plant Research. 5(7): 1051-1061.

Njan, A.A, Adza, B., Agaba, A.G., Byamgaba, D., Diaz, S., dan Bansberg, D.R. (2008). The Analgesic and Antiplasmodial Activities and Toxicology of Vernonia amygdalina. J. Med. Food. 11: 574581.

Nwanjo, H.U. (2005). Efficacy Of Aqueous Leaf Extract Of Vernonia amygdalina On Plasma Lipoprotein And Oxidative Status In Diabetic Rat Models. Nigerian Journal Of Physiological Sciences. 20(1-2): 39-42.

Nwanjo, H.U. dan Nwokoro, E.A. (2004). Antidiabetic And Biochemical Effects Of Aqueous Extract Of Vernonia amygdalina Leaf In Normoglycaemic And Diabetic Rats. J. Innov. Life Sci. (7): 6-10.

Oyugi, D.A., Luo, X., Lee, K.S., Hill, B., dan Izevbigie, E.B. (2009). Activity Markers of The Anti-Breast Carcinoma Cell Growth Fractions of Vernonia amygdalina Extracts. Exp. Biol. Medicine. 234(4): 410-417 